\title{
Inter- and intrasentential anaphora: the case of the Ancient Greek participle*
}

\author{
Corien Bary \\ Radboud University Nijmegen
}

\author{
Dag Haug \\ University of Oslo
}

\begin{abstract}
This paper offers a formal model of the temporal behavior of Ancient Greek participles in their functions as elaborations, frames and independent rhemes. We model how they differ from each other and from main clauses, focusing in particular on the phenomenon of narrative progression. The theory integrates LFG and CDRT, using Glue semantics.
\end{abstract}

Keywords: participles, aspect, temporality, DRT, LFG, Glue Semantics, anaphora, Ancient Greek

\section{Introduction}

In Ancient Greek participles are an important device for structuring a discourse. Used as free adjuncts, they can have three functions. First, a participle may function as an elaboration and provide more information about the event ${ }^{1}$ described in the main clause. Second, in its function as a frame it provides the temporal anchor for the interpretation of the main clause event. Finally, Ancient Greek has participles where other languages like English would use a finite, coordinated clause. We will refer to these participles as independent rhemes. The latter two functions of participles exhibit the phenomenon of narrative progression which has received considerable attention for main clauses (e.g. Hinrichs 1981, Kamp \& Rohrer 1983, Partee 1984, Kamp \& Reyle 1993, and Kamp, van Genabith \& Reyle 2005). As we will see, participles force us to make explicit how this phenomenon, which is normally thought of as occurring at the level of discourse, relates to syntax, information structure, and semantics. In this paper we offer an account of Ancient Greek participles that gives a formal model of the way in which these layers interact.

In order to do that, we combine several frameworks, each dealing with separate components of the grammar. For syntax, we use Lexical-Functional grammar (LFG)

* We thank Markus Egg, Bart Geurts, Mary Dalrymple, and Rob van der Sandt for their useful comments on earlier drafts of this paper. This research is sponsored by the Netherlands Organization for Scientific Research (NWO) [Rubicon grant 446-09-009, Veni grant 275-20-025], the Niels Stensen Stichting, and The Research Council of Norway.

1 In this article we use event in a broad sense, including states, activities et cetera.

C2011 Bary and Haug 
because we believe that a flexible syntactic model is required for free word order languages such as Ancient Greek. Information structure is a notoriously difficult field in formal linguistics. However, since we will only need the notion of new versus given ('anaphoric') information, a dynamic semantic framework like Discourse Representation Theory (DRT) or Compositional Discourse Representation Theory (CDRT) will do. Our choice for the latter is motivated by the fact that we use Glue semantics as the theory of the syntax-semantics interface. Glue semantics requires a semantic language that supports lambda abstraction and application, which CDRT, unlike standard DRT, does.

Our approach to discourse semantics loosely follows Segmented Discourse Representation Theory (SDRT, Asher \& Lascarides 2003) in its combination of dynamic semantics and discourse structure. However, since discourse effects that we find with participles are much more constrained than what we find between main clauses, we believe that they are to a strong degree grammaticalized versions of SDRT's discourse relations, so that they should be represented in the compositional semantics. To deal with this, we will assume that such grammaticalized discourse relations are constructions with their own meaning, bringing into the semantic derivation lambda terms which have much the same semantic effects on the intrasentential semantics as SDRT's relations have between Elementary Discourse Units (EDUs). However, in order not to complicate matters too much, we model discourse relations only in so far as the temporal dimension is concerned.

Although we focus on Ancient Greek participles, the usefulness of the unified framework we develop is not restricted to Ancient Greek, nor to participles. The framework makes it possible to relate four issues that are at the heart of formal semantics and pragmatics: clause linkage, temporal anaphora, narrative progression (which, as we will see, is also connected with the interpretation of aspect), and interactions between information structure, word order and semantics. This combination is arguably also needed to model the interpretation of participles and discourse structuring devices in other languages. As such it contributes to the understanding of the temporal interpretation of a discourse in general.

Section 2 discusses the three functions of Ancient Greek participles. In section 3 we discuss the DRT treatment of narrative progression, followed by a formal analysis of Ancient Greek participles in section 4. Finally, we draw some conclusions in section 5 .

\section{Ancient Greek participles}

Example (1) shows a participle in its function as an elaboration: ${ }^{2}$

2 The glossing follows the Leipzig glossing rules, but often omits details that are not important in the context and uses 'PRT' for particles. References use the abbreviations from Liddell, Scott \& Jones 
Inter- and intrasentential anaphora

grammata graphousi kai logizontai psêphoisi Hellênes

letters.ACC write.PRS.3PL and calculate.PRS.3PL stones.DAT Greeks.NOM

men apo tôn aristerôn epi ta dexia pherontes

PRT from the.GEN left.GEN to the.ACC right.ACC moving.IPFV.PTCP

tên kheira, Aiguptioi de apo tôn dexiôn epi

the.ACC hand.ACC Egyptians.NOM PRT from the.GEN right.GEN to

ta aristera

the.ACC left.ACC

The Greeks write letters and calculate with stones by moving the hand from left to right, whereas the Egyptians (do so) from right to left (Hdt. 2.36.4)

Here the participial clause apo tôn aristerôn epi ta dexia pherontes tên kheira 'moving the hand from left to right' provides more information about the writing and calculating events described in the main clause. This is typical for participles in this function. In discourse terms, they are subordinate to their matrix clause and would attach to it via a subordinating discourse relation. The type of discourse subordination induced by elaborating participles makes them temporally dependent on their matrix verb: the moving of the hand from left to right holds throughout the writing and calculating with stones. Elaborations do not interact with the context but pick up the time of the matrix event. We will see that they differ from the other two functions of participles in this respect. A second difference is that elaboration participles do not provide a new temporal anchor which can be picked up in the following discourse.

Framing participles are anaphoric: they refer to events that have been mentioned in the previous discourse, as in (2), or to events that are easily inferred.

(Alyattes died. Description of something he did during his life.) ...

Teleutêsantos de Aluatteô exedexato tên dying.PFV.PTCP.GEN PRT Alyattes.GEN receive.PST.PFV.3SG the.ACC

basilêiên Kroisos

reign.ACC Croesus.NOM

After Alyattes died Croesus received the reign. (Hdt. 1.26.1)

Temporally, their anaphoric nature makes them dependent on the context for their own temporal reference. Furthermore, it enables them to set the stage for and so provide temporal anchoring for the matrix event. In (2), the dying of Alyattes does not introduce a new time into the discourse: this event has already been mentioned

(1940). In the examples, the participles that are relevant in the context and their English translations are set in bold face. 
and placed in the narrative sequence. On the other hand, Alyattes' death does serve to locate in time the event of Croesus' receiving the reign. Specifically, it does this by moving the narration forward so that we understand the matrix event takes place (just) after the adjunct event. This narrative progression is associated with perfective aspect and not present with imperfective aspect.

Independent rhemes are perhaps the most foreign usage of participles from the perspective of modern European languages. These are participles which present information that is new, just like main verbs, but unlike elaborations they are not discourse subordinated to their matrix, but rather coordinated:

$\begin{array}{lcc}\text { dramôn } & \text { de tis } & \text { kai gemisas } \\ \text { running.PFV.PTCP.NOM PRT some.NOM and filling.PFV.PTCP.NOM } \\ \text { spoggon oxous } & \text { peritheis } & \text { kalamôi } \\ \text { spunge.ACC vinegar.GEN putting.PFV.PTCP.NOM reed.DAT } \\ \text { epotizen } \\ \text { give-to-drink.PST.IPFV.3SG him.ACC saying.IPFV.PTCP.NOM }\end{array}$

Someone ran and filled a sponge with sour wine, put it on a reed, and gave him a drink, saying... (Mk. 15:36)

Such independent rheme participles are typically translated (as above) by coordinations in English. As (3) shows, it is possible to have long sequences of participles describing events leading up to the matrix event in what we will refer to as a serial construction.

When it comes to temporal relations, independent rhemes, like frames, relate to the preceding context. However, since they introduce new events, their time reference is not purely anaphoric, as is the case for frames. Instead they can introduce new times and thus move the narration forward. With regard to the matrix verb, they provide the temporal context, just like in normal narrative sequences where each verb refers to an event which follows the previous one. Thus, in (3), each event, including that of the matrix verb, is understood as taking place (just) after the previously expressed event, due to the phenomenon of narrative progression. In the data of the corpus study in Haug (forthcoming) stacked perfective independent rhemes always induce narrative progression, unlike what is the case between main clauses where this is only a default.

In Haug (forthcoming) it is argued that the three types of participles are distinguished syntactically in Greek. Elaborations appear inside the I' projection, whereas independent rhemes are adjoined to I' and frames appear in spec, IP. The three positions are illustrated in (4): 
Inter- and intrasentential anaphora

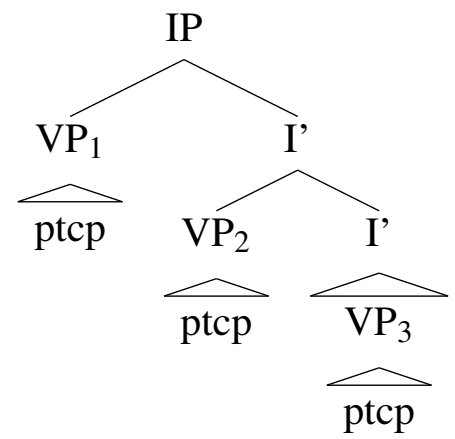

$\mathrm{VP}_{1}$ is a frame, $\mathrm{VP}_{2}$ is an indepedendent rheme and $\mathrm{VP}_{3}$ is an elaboration.

The surface string will often be ambiguous between one or more of the syntactic analyses. For example, an initial participle can either be a frame in the specifier of IP, or left-adjoined to IP. If no material follows which clearly must be outside I', it could even be an elaboration. However, there is a clear tendency for elaborating participles to occur to the right of their heads. Furthermore, although independent rhemes are sometimes right-adjoined, left adjunction is by far the most common option. In practice, then, the major ambiguity is that between frames and independent rhemes in sentence initial position.

Table 1 sums up the main properties of the different types of participles. In this paper we focus on the dimension of temporal connections. Although we believe these effects are ultimately due to information structure, we can 'bypass' information structure in our analysis since, as we have seen, there seems to be a relatively straightforward mapping to syntax in this particular case. The phenomena we want

\begin{tabular}{l|lll}
\hline & Elaborations & Independent rhemes & Frames \\
\hline Information status & new & new & old \\
Discourse relation & subordinated & coordinated & coordinated \\
Temporal anchor & matrix & context & anaphoric \\
& & (loose relation) & (strict relation)
\end{tabular}

Table 1 Overview of participle types

to account for in particular are:

- the temporal anchoring of events inside and across sentences, both what anchors they can relate to and with what temporal relations;

- the obligatory narrative progression with independent rhemes and frames;

- the obligatory intersentential bindings of all participles except the leftmost one in a serial construction;

- the effects of participles on the further narration and the extent to which they provide anchors for it. 


\section{Tense, aspect, and narrative progression in CDRT}

In our analysis we combine LFG (Kaplan \& Bresnan 1982, Bresnan 2001, Dalrymple 2001) with CDRT (Muskens 1996), using Glue semantics (Dalrymple 1999) as a theory of the syntax-semantics interface. For reasons of space we cannot give a proper introduction into these frameworks. The only things we discuss before we start with the actual analysis in the next section are the semantics of tense and aspect we will use and the DRT treatment of narrative progression with main clauses (heavily based on Kamp et al. 2005). This discussion will make clear the similarities and differences between main clauses and participial clauses. All is recast in CDRT terms.

Following Klein (1994), we use the term topic time for the time about which the utterance is made. Tense indicates the relation between the topic time and the moment of utterance. More in particular, past tense indicates that the topic time precedes the moment of utterance, present tense indicates that the topic time is the moment of utterance, and future tense that the topic time follows the moment of utterance. Aspect also concerns the relation between the topic time and a second time, namely the time of the event (the time that an event actually takes up) (Klein 1994, Gerö \& von Stechow 2003, Paslawska \& von Stechow 2003). More precisely, perfective aspect indicates that the event is completed, hence the time of the event is included in the topic time. Imperfective aspect, on the other hand, indicates than the event may continue after the topic time. For a motivation of this kind of temporal analysis of aspect in Ancient Greek, we refer the reader to Bary (2009), although the exact temporal relations used there are somewhat different from the ones we use in this paper.

In CDRT terms, aspect becomes:
a. $\lambda \mathrm{P} \lambda \mathrm{t}\left[\frac{\mathrm{e}}{\tau(\mathrm{e}) \supseteq \mathrm{t}} \oplus \mathrm{P}(\mathrm{e})\right]$
(imperfective aspect)

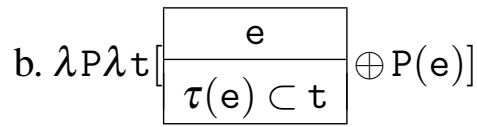
(perfective aspect)

Aspect is a function from sets of events to sets of (topic) times such that a certain relation (as specified above) holds between the time of the events and the topic times. $^{3}$

Tense then becomes:

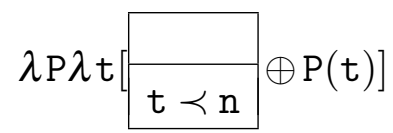

3 Properly speaking, $t$ is not a variable over times, but over registers for temporal type individuals. See Muskens (1996) for details. 
Inter- and intrasentential anaphora

Application of aspect gives us a set of times. The role of temporal morphology, then, is to intersect this set with the set of all past, present or future times, respectively.

But the indefinite time introduced by tense is normally not precise enough to allow for an interpretation; the time variable also needs to be anchored in the context, unless there are specific clues inside the sentence, such as frame adverbials or as we shall argue, framing participles, which already fulfill this purpose. To model this, sentences come with the following semantics, based on Kamp et al. (2005), which for lack of a better term, we shall refer to as the semantics of finiteness:

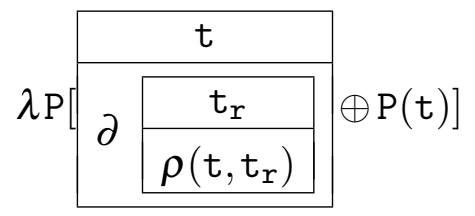

The complex condition prefixed with $\partial$ signals a presupposition and can be informally read as an instruction to find a suitable reference time $t_{r}$ and a relation $\rho$ to anchor the topic time $t$ in the context. However, original CDRT does not deal with presuppositions and assumes for anaphors such as $t_{r}$ that the syntax supplies coindexation with the antecedent. Therefore there is no model-theoretic interpretation for such complex conditions, unlike the other expressions of our meaning language. While this is less than satisfactory for a final account, we believe a full treatment of presuppositions in CDRT would complicate matters too much. ${ }^{4}$

As we shall see later, it is important that finiteness only is a default case which applies when there is no overt anchoring of the topic time through adverbs or framing participles. Glue semantics will offer us the possibility to model this as 'anchoring of last resort'.

Let's see how this works for (8):

$$
\begin{aligned}
& \text { kai duo te anti henos nēous tēi Athēnaiēi } \\
& \text { PRT two.ACC PRT instead.of one.GEN temples.ACC the.DAT Athena.DAT } \\
& \text { oikodomēse ho Aluattēs en tēi Assēsōi, } \\
& \text { build.PST.AOR.3SG the.NOM Alyattes.NOM in the.DAT Assessos.DAT }
\end{aligned}
$$

4 There are several options one could entertain. First, we could actually use coindexation as in Muskens 1996 (see also Muskens 2011). Second, Haug (2011) recasts CDRT in a partial theory of types which allows for underspecification of anaphoric dependencies. Third, van Leusen \& Muskens (2003) show how the procedural aspects of DRT, which are important in DRT's treatment of presuppositions, among other things, can be mimicked in a declarative way, using a hybrid theory combining the binding and satisfaction theories of presuppostion. Note that although we do not use coindexation here, we implicitly assume that the syntax provides unique indices on tokens, i.e. it is able to discern different tokens of the same type. This justifies the use of, for example, $e_{f i l l}, e_{p u t}$, and $e_{\text {drink }}$ in (26), giving the impression of variable renaming, although these terms are in fact constants. 
autos te ek tēs nousou anestē.

self.NOM PRT from the.GEN illness.GEN rise.from.PST.AOR.3SG

Alyattes built not one but two temples of Athena at Assesos, and recovered from his illness.

Hdt. 1.22.4

Here, as often with two perfective main clauses, the interpretation is that the recovery follows the building. Simplifying the semantics of the predicates themselves, the representation of the first clause becomes:
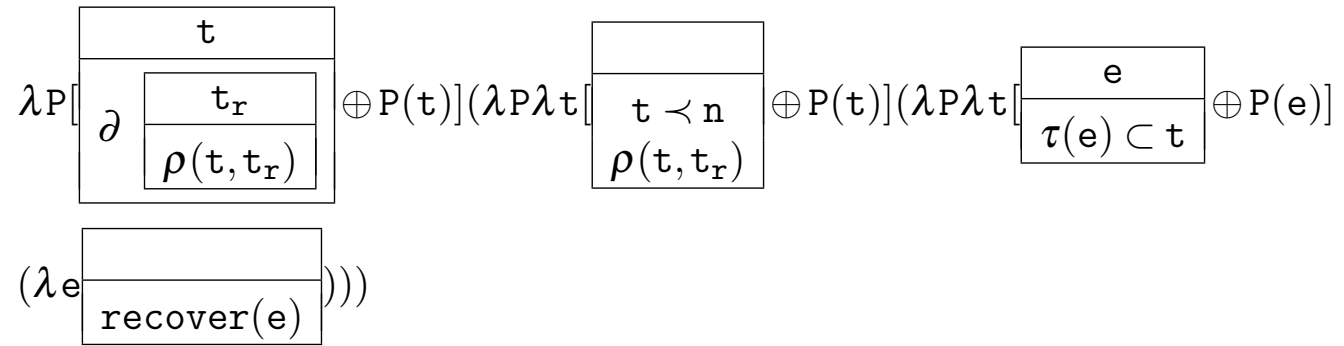

which can be reduced to (10) (through functional application and merging ' $\oplus$ '):

\begin{tabular}{|c|}
\hline $\mathrm{t}_{1} \mathrm{e}_{1}$ \\
\hline recover $\left(\mathrm{e}_{1}\right)$ \\
$\tau\left(\mathrm{e}_{1}\right) \subset \mathrm{t}_{1}$ \\
$\mathrm{t}_{1} \prec \mathrm{n}$ \\
$\partial \frac{\mathrm{t}_{\mathrm{r}}}{\mathrm{d}\left(\mathrm{t}_{1}, \mathrm{t}_{\mathrm{r}}\right)}$ \\
\hline
\end{tabular}

Similarly, the representation of the second clause becomes:

\begin{tabular}{|c|c|}
\hline & $t_{2} e_{2}$ \\
\hline & $\operatorname{uild}\left(e_{2}\right)$ \\
\hline & $\begin{array}{c}\left(\mathrm{e}_{2}\right) \subset \mathrm{t}_{2} \\
\mathrm{t}_{2} \prec \mathrm{n}\end{array}$ \\
\hline$\partial$ & $t_{r}$ \\
\hline$O$ & $\rho\left(t_{2}, t_{r}\right)$ \\
\hline
\end{tabular}

Although the first clause is of course also temporally anchored in the context, we focus on the anchoring of the second clause. After the two representations have been merged, $t_{r}$ is to be identified with a previously established time and $\rho$ is to be specified. Here, as often, the topic time of the last mentioned event serves as the reference time: $t_{r}$ binds to $t_{1}$. However, this is not always the case. In (12), for example, the event of paying described in the third sentence is intuitively related to 
Inter- and intrasentential anaphora

the event of buying mentioned by the first sentence rather than to the event of seeing the bike in the newspaper, mentioned in between.

(12) Max bought a new bike. He had seen it in the newspaper. He paid 300 euros for it.

Therefore, the resolution to the topic time of the last mentioned event cannot be more than a default.

Aspect plays a role in the specification of the temporal relation $\rho$. With perfective aspect the default is that $\rho$ is specified as $\prec$ (the reference time precedes the topic time of the current utterance), with imperfective as $\subseteq$ (the reference time is included in the topic time). For (8), this gives the desired result: the recovery follows the building event. But again, this rule cannot be more than a default. As (13) (from Asher \& Lascarides 2003) and the Greek (14) show, aspect does not uniquely determine the temporal relation, as a sentence in perfective aspect can refer to a time preceding that of the previous sentence.

Max fell. John pushed him.

diapherousi de sphi epi isês ton polemon prevail.IPFV.PTCP.DAT PRT they.DAT PREP equal.GEN the.ACC war.ACC tôi hektôi eteï sumbolês genomenês the.DAT sixth.DAT year.DAT encounter.GEN take.place.PFV.PTCP.GEN sunêneike hôste, tês makhês sunesteôsês, happen.PST.PFV.3SG that the.GEN battle.GEN be.joined.PRF.PTCP.GEN tên hêmerên exapinês nukta genesthai. Tên de the.ACC day.ACC suddenly night.ACC be.PFV.INF the.ACC PRT metallagên tautên tês hêmerês Thalês ho change.ACC that.ACC the.GEN day.GEN Thales.NOM the.NOM Milêsios toisi Iôsi proêgoreuse esesthai, Milesian.NOM the.DAT Ionians.DAT foretell.PST.PFV.3SG be.FUT.INF ouron prothemenos eniauton touton en tô $i$ dê kai bound.ACC fix.PFV.PTCP.NOM year.ACC that.ACC in REL.DAT PRT PRT egeneto hê metabole be.PST.PFV.3SG the.NOM change.NOM

They were still warring with equal success, when it happened, at an encounter which occurred in the sixth year, that during the battle the day was suddenly turned to night. Thales of Miletus had foretold this loss of daylight to the Ionians, fixing it within the year in which the change did indeed happen. (Hdt. 1.74.2) 
In addition to aspect, other factors play a role as well, among which knowledge of the 'normal course of events'. Loosely following the SDRT framework, we can assume that the interpreter of (13) connects the two sentences with the rhetorical relation Explanation, which has the semantic consequence that the second event precedes the first. The $\rho$ can therefore be seen as the temporal dimension of a discourse relation which is inferred in the context and which might have other semantic consequences that we do not model.

Participles behave like main clauses in many respects. For one thing, they also give rise to narrative progression and much of what we have seen in this section will come back in their analysis. However, there are two important differences. First, participles cannot be skipped over in the search for an antecendent. Whereas in (12) the event of paying described in the third sentence is intuitively related to the buying event mentioned by the first sentence rather than to the seeing event, this is impossible with a participle, as (15) shows:

(15) \# Max bought a new bike. Having seen it in the newspaper, he paid 300 euros for it.

The reason why (15) is odd is exactly that we are forced to infer a discourse relation between the paying of 300 euros and the seeing of the bike in the newspaper, an inference that world knowledge does not support. Second, as we have seen in section 2, narrative progression is obligatory rather than optional with Ancient Greek perfective framing and independent rheme participles.

\section{Analysis}

\subsection{Independent rhemes}

Independent rheme participles are those which are discourse coordinated with their matrix. This means that they are independent assertions of events tied to their own topic times, and so they introduce time referents into the discourse. Such participles can be 'stacked' and thus occur in sequences which are similar to sequences of finite verbs.

However, there is a difference in that in sequences of participles and finite verbs such as (3) each verb obligatorily relates to the preceding verb. Unlike the case with main clauses, it is not possible to 'skip' a verb in the sequence. We can capture both this fact and the possibility of having several independent rheme participles by having the independent rheme construction require that

(16) the participle provides the reference time for the head of the verbal projection to its right. 
Inter- and intrasentential anaphora

To formalize the concept of 'verbal projection to the right', we define a metavariable $>^{5}$ which is only defined for nodes that have a sister node to the right. If that is the case, $>$ refers to

i. the f-structure of the left-most daughter of the sister to the right if the sister to the right does not dominate a node of the same category and one bar level lower than itself (i.e. the sister to the right results from an adjunction)

ii. else, of the f-structure of the sister to the right

Furthermore, we need to be able to refer to the f-structure of which another f-structure is an adjunct. We use standard LFG notation here, e.g. ADJ $\in \downarrow$, meaning 'the f-structure which contains an ADJ attribute whose value is a set containing $\downarrow$ '. The arrow $\downarrow$ is a meta-variable over f-structures: it refers to the f-structure of its own node (similarly, $\uparrow$ would refer to the f-structure of its mother mode).

With this notation in place, we can formalize (16) as in (17):

$$
\begin{aligned}
& \text { indrheme: } \lambda \mathrm{P} \lambda \mathrm{Q} \lambda \mathrm{t}[\mathrm{P}(\mathrm{t}) \oplus \mathrm{Q}(\mathrm{t})]: \\
& \left(T_{\downarrow} \multimap B_{\downarrow}\right) \multimap\left(T_{>} \multimap B_{\mathrm{ADJ} \in \downarrow}\right) \multimap\left(T_{\downarrow} \multimap B_{\mathrm{ADJ} \in \downarrow}\right)
\end{aligned}
$$

In Glue semantics, meaning constructors such as (17) consists of two parts: the semantic representation before the colon (here a CDRT term) is paired with a glue term (an expression of linear logic) after the colon. The glue terms function as types under the 'propositions as types' interpretation (also known as the Curry-Howard isomorphism) which is available for constructive logics. In (17) we have two base type constructors, $B$ for booleans (truth values) and $T$ for times. For reasons of space, we don't give the f-structures (normally labeled $f, g, h$, etc.) themselves in this paper. $B(f)$ will be a boolean type associated with the f-structure labelled $f$. For brevity and to avoid parenthesis clutter we write $B_{f}$. As we will see, the fact that the types are constructed from syntactic entities allows us a purely type-driven semantic composition.

$\multimap$ is the connective linear implication. Unlike e.g. the case of material implication of classical logic, the modus ponens (elimination) rule for linear implication consumes the antecedent. In other words, from $A \multimap B$ and $A$ we can conclude $B$, but not $A$ and $B$. Although we will not consider model theory for linear logic here, we can note that on a natural interpretation, linear logic is a logic of resources, which

5 This is not standard LFG notation, but rather a convenient abbreviation which could be expressed, if somewhat clumsily, in standard notation. It is similar to $*>$ (Dalrymple 2001: 120), which refers to the sister to the right of the current node, but differs from it in its special behavior whenever the sister to the right is an adjunction, as well as in incorporating the $\phi$ projection so that it always refers to an f-structure rather than to a c-structure node. 
disappear when consumed, rather than truths, which can be reused at will. This resource sensitivity makes linear logic particularly apt to model semantic composition, where each element can be used only once. The relation between the part of (17) before the colon and that after the colon is that functional application corresponds to the elimination rule for linear implication (modus ponens), and lambda abstraction to the introduction rule.

For the semantic part, (17) states that both DRSs should be interpreted with respect to the same time interval. However, as discussed before, we get narrative progression whenever the participle is perfective. We capture this by having independent rhemes (and frames) introduce the meaning constructor in (18) if the aspect of the participle is perfective.

$$
\begin{aligned}
& \operatorname{narprog} \lambda \mathrm{R} \lambda \mathrm{P} \lambda \mathrm{Q}\left[\mathrm{R}(\mathrm{P})\left(\lambda \mathrm{t}\left[\frac{\mathrm{t}^{\prime}}{\mathrm{t} \supset \mathrm{t}^{\prime}} \oplus \mathrm{Q}\left(\mathrm{t}^{\prime}\right)\right]\right]\right): \\
& \left(\left(\left(T_{\downarrow} \multimap B_{\downarrow}\right) \multimap\left(T_{>} \multimap B_{\mathrm{ADJ} \in \downarrow}\right) \multimap\left(T_{\downarrow} \multimap B_{\mathrm{ADJ} \in \downarrow}\right)\right) \multimap\right. \\
& \left.\left(\left(T_{\downarrow} \multimap B_{\downarrow}\right) \multimap\left(T_{>} \multimap B_{\mathrm{ADJ} \in \downarrow}\right) \multimap\left(T_{\downarrow} \multimap B_{\mathrm{ADJ} \in \downarrow}\right)\right)\right)
\end{aligned}
$$

This meaning constructor ensures that perfective participles push the reference time forward in serial constructions. It appears only in cases of independent rheme and framing participles, as these constructions seem to have grammaticalized narrative progression. Narrative progression here quantifies into the second argument of the independent rheme construction and ensures that it does not pick up the topic time of the first, but rather a time immediately following (' $\supset \prec$ '). The reader can verify that the effect of combining (17) and (18) is (19):

$$
\begin{aligned}
& \text { narindrheme: } \lambda \mathrm{P} \lambda \mathrm{Q} \lambda \mathrm{t}\left[\mathrm{P}(\mathrm{t}) \oplus \frac{\mathrm{t}^{\prime}}{\mathrm{t} \supset \prec \mathrm{t}^{\prime}} \oplus \mathrm{Q}\left(\mathrm{t}^{\prime}\right)\right]: \\
& \left(T_{\downarrow} \multimap B_{\downarrow}\right) \multimap\left(T_{>} \multimap B_{\mathrm{ADJ} \in \downarrow}\right) \multimap\left(T_{\downarrow} \multimap B_{\mathrm{ADJ} \in \downarrow}\right)
\end{aligned}
$$

We will use this meaning constructor directly in our tree to avoid unnecessary calculations.

Let's work out example (20) $(=(3)$ without the first participle to reduce the tree somewhat):

$$
\text { gemisas spoggon oxous peritheis }
$$

filling.PFV.PTCP.NOM spunge.ACC vinegar.GEN putting.PFV.PTCP.NOM

kalamôi epotizen auton

reed.DAT give-to-drink.PST.IPFV.3SG him.ACC

(Someone ran and) filled a sponge with sour wine, put it on a reed, and gave him a drink, (saying) ... 
Inter- and intrasentential anaphora

Ignoring the thematic arguments, this sentence has the following c-structure and semantic annotation. To reduce clutter, aspect has already been combined with its verb; for the matrix verb, tense but not finiteness has been applied.

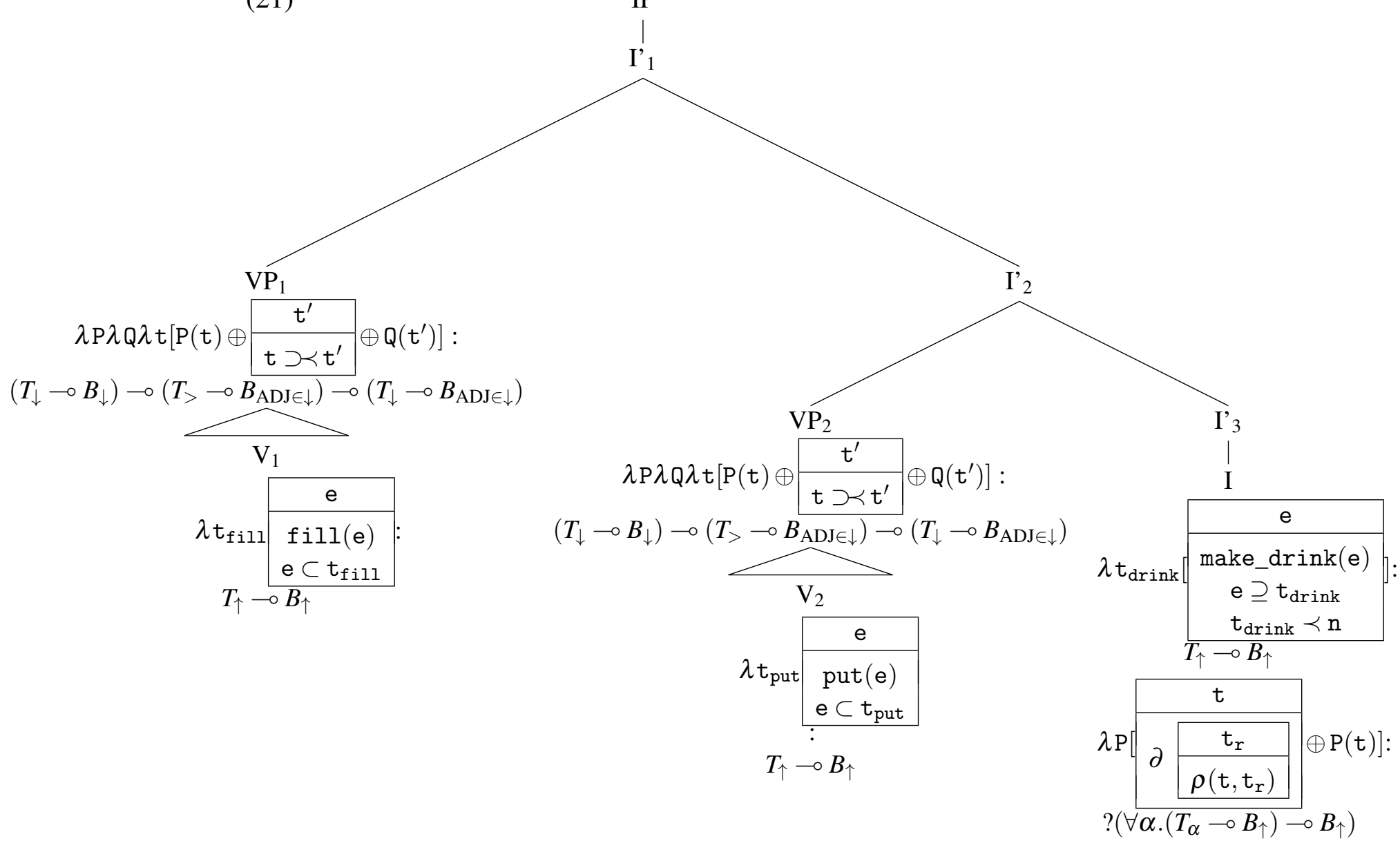

The ? exponential signals optionality for the finiteness meaning constructor: it indicates that this resource may but need not be used. ${ }^{6}$ The quantifier $\forall$ in linear logic is closer to 'any' than to 'all': $\alpha$ can be instantiated to any f-structure label we want, but only to one. It is useful in modeling temporal anchoring: the fact that we have a finite main clause tells us that something needs to be anchored in the discourse context, but not necessarily the finite verb itself. As we will see, it is rather the leftmost verb that must be anchored in the context.

6 Rather than encoding the optionality of the finiteness meaning in the linear logic by means of the ? exponential, we could also encode the entire annotation as optional and keep the linear logic simpler, since the LFG language allows node annotations to be stated in a regular language. 
The meaning constructors get instantiated in the following way, using $f$ for the f-structure of fill, $p$ for that of put and $d$ for that of make drink:

$$
\begin{array}{ll}
\text { node } & \text { constructor } \\
\hline \mathrm{V}_{1} & T_{f} \multimap B_{f} \\
\mathrm{VP}_{1} & \left(T_{f} \multimap B_{f}\right) \multimap\left(T_{p} \multimap B_{d}\right) \multimap\left(T_{f} \multimap B_{d}\right) \\
\mathrm{V}_{2} & T_{p} \multimap B_{p} \\
\mathrm{VP}_{2} & \left(T_{p} \multimap B_{p}\right) \multimap\left(T_{d} \multimap B_{d}\right) \multimap\left(T_{p} \multimap B_{d}\right) \\
\mathrm{I} & T_{d} \multimap B_{d} \\
& ?\left(\forall \alpha .\left(T_{\alpha} \multimap B_{d}\right) \multimap B_{d}\right)
\end{array}
$$

There is only one way to put these constructors together:

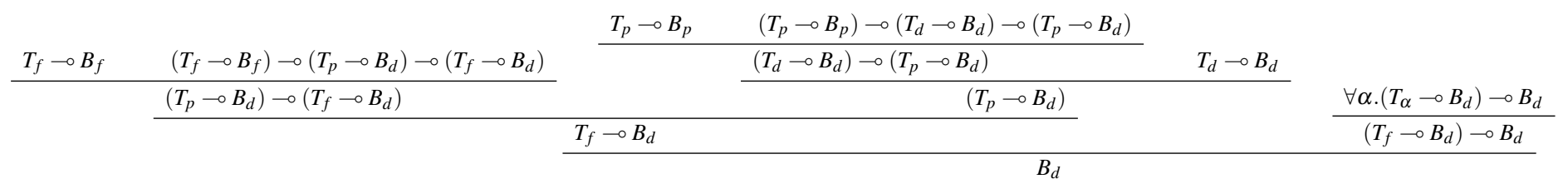

Corresponding to the two top splits in the middle branch of this proof tree, we get the following corresponding functional application:

$$
\begin{aligned}
& \lambda \mathrm{P} \lambda \mathrm{Q} \lambda \mathrm{t}\left[\mathrm{P}(\mathrm{t}) \oplus \frac{\mathrm{t}^{\prime}}{\mathrm{t} \supset \prec \mathrm{t}^{\prime}} \oplus \mathrm{Q}\left(\mathrm{t}^{\prime}\right)\right]\left(\lambda \mathrm{t}_{\text {put }} \begin{array}{c|}
\begin{array}{c}
\mathrm{e}_{\text {put }} \\
\mathrm{put}\left(\mathrm{e}_{\text {put }}\right) \\
\mathrm{e} \subset \mathrm{t}_{\text {put }}
\end{array} \\
\hline
\end{array}\right.
\end{aligned}
$$

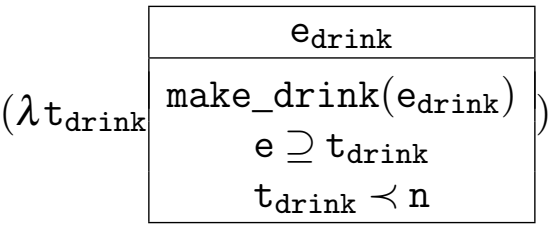

which gives:

$$
\begin{array}{|c|c|}
\hline t_{\text {drink }} e_{\text {put }} e_{\text {drink }} \\
\hline t_{\text {put }} \supset \prec t_{\text {drink }} \\
\text { put }\left(e_{\text {put }}\right) \\
e_{\text {put }} \subset t_{\text {put }} \\
\text { make_drink }\left(e_{\text {drink }}\right) \\
e_{\text {drink }} \supseteq t_{\text {drink }} \\
t_{\text {drink }} \prec n \\
\hline
\end{array}
$$

Further combination with fill (the left part of the proof tree) and finiteness (which is used here since it is necessary for the proof of a sentence meaning) yields (26): 
Inter- and intrasentential anaphora

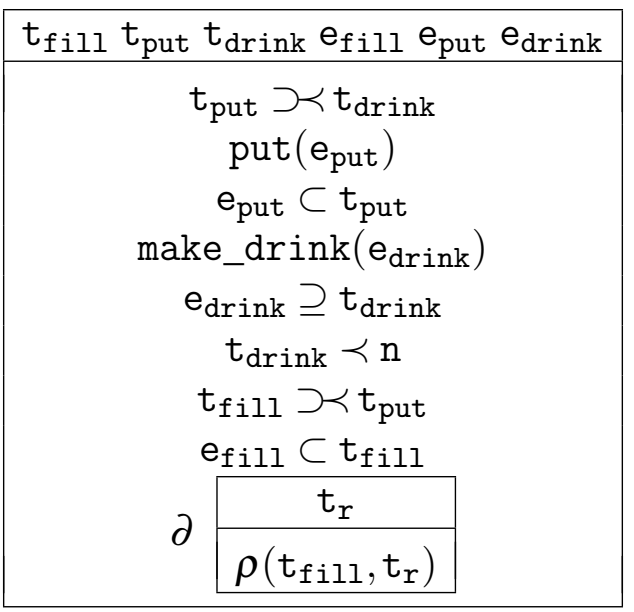

We see that we correctly get a sequence of events, with each participle providing the reference time for the next verb; only the leftmost participle interacts with the context, in the sense that its reference time $\left(t_{r}\right)$ must be anaphorically bound. This is an effect of the Glue logic: after consuming the participle's contribution, the independent rheme construction is of the type $\left(T_{>} \multimap B_{\mathrm{ADJ} \in \downarrow}\right) \multimap\left(T_{\downarrow} \multimap B_{\mathrm{ADJ} \in \downarrow}\right)$ : this means it is looking for a sentence meaning $\left(B_{\mathrm{ADJ} \in \downarrow}\right)$ dependent on the topic time of the verb to its right $\left(T_{>}\right)$to produce a sentence meaning dependent on its own topic time $\left(T_{\downarrow}\right)$.

\subsection{Frames}

Framing participles are like independent rhemes in many respects. They always induce narrative progression when perfective and they always set the reference time for the next verb in line. They differ, however, in that not only the time variable, but also the event must be bound or accommodated in the context. In this way it serves as the anchor for the interpretation of the event in the main clause. In contrast to the semantics of the independent rheme construction (17), the frame construction (27) introduces a presupposition/anaphoric element, as $\partial$ indicates.

$$
\begin{aligned}
& \text { frame: } \lambda \mathrm{P} \lambda \mathrm{Q}[\partial[\stackrel{\mathrm{t}}{\square} \oplus \mathrm{P}(\mathrm{t})] \oplus \mathrm{Q}(\mathrm{t})]: \\
& \left(T_{\downarrow} \multimap B_{\downarrow}\right) \multimap\left(T_{>} \multimap B_{\mathrm{ADJ} \in \downarrow}\right) \multimap\left(B_{\mathrm{ADJ} \in \downarrow}\right)
\end{aligned}
$$

Notice that the final output of this constructor differs from that of independent rhemes: the end result is a boolean type meaning $\left(B_{\mathrm{ADJ} \in \downarrow}\right)$, i.e. a meaning which is already anchored in the context without using the default finite constructor.

Again, a frame construction can combine with the narrative progression effect (18) to yield (28): 
(28)

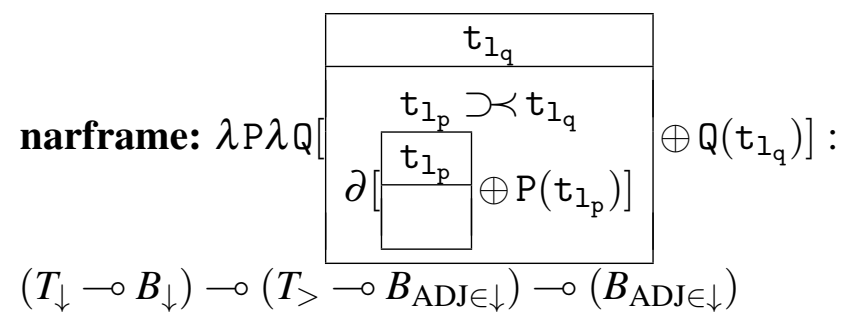

For our example (2), here repeated as (29), this gives the annotated tree in (30):

Teleutêsantos de Aluatteô exedexato tên dying.PFV.PTCP.GEN PRT Alyattes.GEN receive.PST.PFV.3SG the.ACC

basilêiên Kroisos

reign.ACC Croesus.NOM

After Alyattes died Croesus received the reign.

(30)

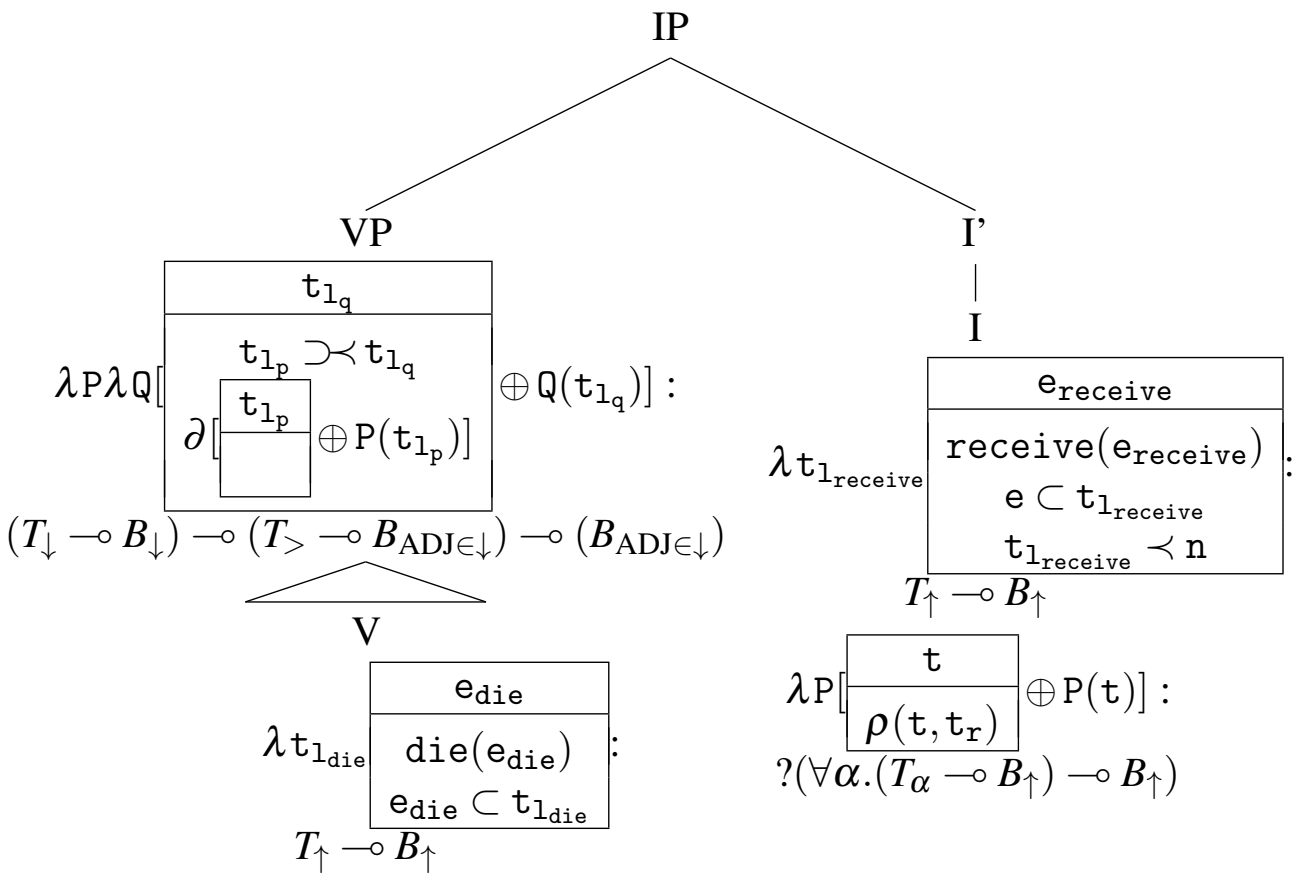

The condition

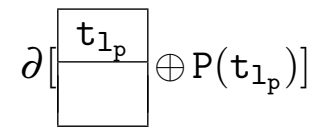

can informally be read as an instruction to find a time and an event satisfying $\mathrm{P}$ in the context. Since (31) applies to the semantics of the participle teleutêsantos 'having died', this involves finding a dying event. The tree then yields the following lambda term: 
Inter- and intrasentential anaphora

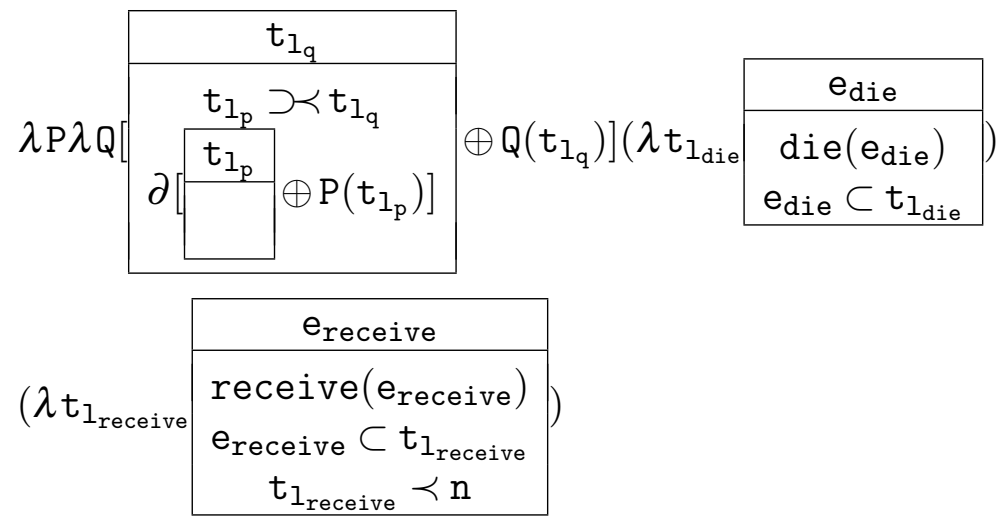

which reduces to

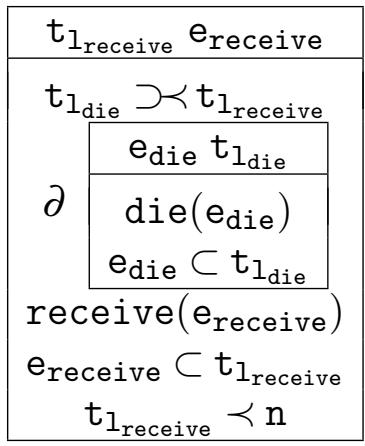

Notice that in this case, unlike for independent rhemes (and, as we will see, elaborations), there is actually no room for finiteness to introduce a $\rho$ relation: the temporal relation to the context is instead specified directly by the framing construction, which leaves a type $B$ meaning rather than a type $T \multimap B$.

\subsection{Elaboration}

From the perspective of temporal relations, the important fact about the elaboration construction is that the participle is temporally dependent on the matrix event. A consequence of this is that we infer temporal overlap between the events, even when the participle is perfective. The elaboration construction (34) captures this fact:

$$
\begin{aligned}
& \text { elab: } \lambda \mathrm{P} \lambda \mathrm{Q} \lambda \mathrm{e}[\mathrm{P}(\tau(\mathrm{e})) \oplus \mathrm{Q}(\mathrm{e})]:\left(T_{\downarrow} \multimap B_{\downarrow}\right) \multimap\left(( E V _ { \uparrow } \multimap B _ { \uparrow } ) \multimap \left(E V_{\uparrow} \multimap\right.\right. \\
& \left.\left.B_{\uparrow}\right)\right)
\end{aligned}
$$

In this context $\downarrow$ refers to the f-structure of the participle and $\uparrow$ to the f-structure of the matrix verb. What the elaboration construction does, then, is to take the set of times associated with the participle after application of aspect $\left(T_{\downarrow} \multimap B_{\downarrow}\right)$ and construct something which can intersect with the set of events denoted by the matrix verb before application of aspect $\left(\left(E V_{\uparrow} \multimap B_{\uparrow}\right) \multimap\left(E V_{\uparrow} \multimap B_{\uparrow}\right)\right)$. 
For (35), the composition of the elab constructor with the meaning of the participle and that of the main verb yields the DRS in (36).

$\begin{array}{lll}\text { elalei } \quad \text { eulogôn } & \text { ton theon } \\ \text { speak.PST.IPVF.3S praising.IPFV.PTCP.NOM the.ACC god.ACC }\end{array}$

He was speaking praising god. (Lk. 1.64)

\begin{tabular}{|c|}
\hline ef $\mathrm{t}$ \\
\hline speak $(\mathrm{e})$ \\
$\tau(\mathrm{e}) \supseteq \mathrm{t}$ \\
$\mathrm{t} \prec \mathrm{n}$ \\
$\frac{\mathrm{t}_{\mathrm{r}}}{2}$ \\
\hline$\rho\left(\mathrm{t}, \mathrm{t}_{\mathrm{r}}\right)$ \\
$\mathrm{praise}(\mathrm{f})$ \\
$\tau(\mathrm{f}) \supseteq \tau(\mathrm{e})$ \\
\hline
\end{tabular}

As (36) shows, elaborating participles pick up the time of their matrix verb instead of a time from the context. Here, the speaking and praising events are at least overlapping. Furthermore, although the participle does introduce an event discourse referent, it does not introduce a time discourse referent. This correctly predicts that the time interval associated with an elaborating participle cannot be picked up in the further discourse. ${ }^{7}$

\section{Conclusion}

In this paper, we modeled the discourse behavior of the three different functions of free adjunct participles in Ancient Greek. Focusing on their temporal dimensions, we modeled a difference in (i) the temporal relations with respect to the event of the matrix clause, (ii) the possibilities of stacking, (iii) the relation to the preceding discourse (old versus new information), and (iv) to the following discourse (whether the time of the participle event is available for anaphoric uptake). The combination of LFG and CDRT using Glue semantics made it possible to provide an analysis of these phenomena all the way from syntax to discourse incorporating both intersentential and intrasentential binding. The latter is captured via explicit meaning constructors for the various constructions that participles can enter into. Only in the case that there is no intrasentential time to bind to will finiteness do its work and provide for intersentential binding, exploiting the underlying dynamic semantics.

7 Negative data are of course always problematic in a language with no native speakers such as Ancient Greek, but this generalization builds on a rather solid number of examples. 
Inter- and intrasentential anaphora

\section{References}

Asher, Nicholas \& Alex Lascarides. 2003. Logics of Conversation. Cambridge: Cambridge University Press.

Bary, Corien. 2009. Aspect in Ancient Greek. A Semantic Analysis of the Aorist and Imperfective: Radboud Universiteit Nijmegen dissertation. http://webdoc.ubn. ru.nl/mono/b/bary_c/aspeinang.pdf.

Bresnan, Joan. 2001. Lexical-Functional Syntax. Oxford: Blackwell.

Dalrymple, Mary (ed.). 1999. Semantics and Syntax in Lexical Functional Grammar. Cambridge, MA: MIT Press.

Dalrymple, Mary. 2001. Lexical Functional Grammar. New York: Academic Press. Gerö, Eva-Carin \& Arnim von Stechow. 2003. Tense in time: the Greek perfect. In Regine Eckardt, Klaus von Heusinger \& Christoph Schwarze (eds.), Words in Time: Diachronic Semantics from Different Points of View, 251-269. Berlin: Mouton de Gruyter.

Haug, Dag. 2011. Partial CDRT for anaphora and presuppositions. Manuscript, University of Oslo.

Haug, Dag. Forthcoming. Open verb-based adjuncts in New Testament Greek and the Latin of the Vulgate. In Cathrine Fabricius-Hansen \& Dag Haug (eds.), Big Events and Small Clauses, Berlin: Mouton de Gruyter.

Hinrichs, Erhard. 1981. Temporale Anaphora im Englischen. Zulassungsarbeit Universität Tübingen.

Kamp, Hans \& Uwe Reyle. 1993. From Discourse to Logic. Dordrecht: Kluwer.

Kamp, Hans \& Christian Rohrer. 1983. Tense in texts. In R. Bäuerle, C. Schwarze \& A. von Stechow (eds.), Meaning, Use, and Interpretation of Language, 250-269. Berlin: de Gruyter.

Kamp, Hans, Josef van Genabith \& Uwe Reyle. 2005. Discourse Representation Theory. In D. M. Gabbay \& F. Günthner (eds.), Handbook of Philosophical Logic, Dordrecht: Springer. http://www.ims.uni-stuttgart.de/\%7Euwe/Papers/ DRT.pdf.

Kaplan, Ronald M. \& Joan Bresnan. 1982. Lexical-functional grammar: a formal system for grammatical representation. In The Mental Representation of Grammatical Relations, 173-281. Cambridge, MA: MIT Press. http://citeseer.ist.psu. edu/viewdoc/download?doi=10.1.1.70.3002\&rep=rep1\&type=pdf.

Klein, Wolfgang. 1994. Time in language. London and New York: Routledge.

van Leusen, Noor \& Reinhard Muskens. 2003. Construction by description in discourse representation. In Jaroslav Peregrin (ed.), Meaning: The Dynamic Turn, 33-65. Amsterdam: Elsevier. http://citeseerx.ist.psu.edu/viewdoc/summary? doi=10.1.1.1.6394.

Liddell, Henry George, Robert Scott \& Henry Stuart Jones. 1940. A Greek-English 
Lexicon. Oxford: Clarendon. http://www.lib.uchicago.edu/efts/PERSEUS/ Reference/lsj.html.

Muskens, Reinhard. 1996. Combining Montague Semantics and Discourse Representations. Linguistics and Philosophy 19. 143-186. http://cogprints.org/4715/ 2/combining.pdf.

Muskens, Reinhard. 2011. A squib on anaphora and coindexing. Linguistics and Philosophy 34. 85-89.

Partee, Barbara Hall. 1984. Nominal and temporal anaphora. Linguistics and Philosophy 7. 243-286.

Paslawska, Alla \& Arnim von Stechow. 2003. Perfect readings in Russian. In Artemis Alexiadou, Monika Rathert \& Arnim von Stechow (eds.), Perfect Explorations, 307-362. Berlin: Mouton de Gruyter. http://citeseerx.ist.psu.edu/ viewdoc/summary?doi=10.1.1.134.8067\&rank=1.

Corien Bary

Faculteit Filosofie

Postbus 9103

6500 HD Nijmegen

The Netherlands

c.bary@phil.ru.nl
Dag Haug

Gresk og latin

Postboks 1020 Blindern

0315 Oslo

Norway

d.t.t.haug@ifikk.uio.no 